\title{
PELATIHAN DESAIN GRAFIS SEBAGAI MEDIA DALAM KEMUDAHAN PENYAMPAIAN SYIAR ISLAM
}

\author{
Juanita \\ juanitamstr@gmail.com \\ E. Supriyatno \\ elingsy@gmail.com
}

\section{UNIVERSITAS MUHAMMADIYAH PURWOKERTO}

\begin{abstract}
ABSTRAK
Dakwah yang menarik dan kemudahan penyampaian syiar khususnya pada generasi muda sangat diperlukan. Penguasaan teknologi komputer khususnya desain grafis menjadi hal penting dalam era digital yang mendukung penyampaian syiar. Kemampuan pengurus Nasyiatul Aisyiyah Banyumas dalam desain grafis penting dalam syiar membidik generasi muda. Pelatihan desain grafis pada Pengurus Nasyiatul Aisiyah Kabupaten Banyumas memanfaatkan Microsoft Power Point agar lebih mudah dipahami. Metode yang digunakan melalui pelatihan/tutorial, praktek dan demonstrasi. Hasil pelatihan diperoleh manfaat pada peningkatan kemampuan desain grafis yang mendukung penyampaian syiar dan mendukung pekerjaan khususnya pada kegiatan organisasi.
\end{abstract}

Kata kunci: Dakwah, Generasi Muda, Desain Grafis, Nasyiatul Aisyiyah.

\section{PENDAHULUAN}

Al Qur'an Surat Al hajj ayat 32 yang artinya "Demikianlah (perintah Allah). Dan barangsiapa mengagungkan syiar-syiar Allah, maka sesungguhnya timbul dari ketakwaan hati", sedangkan dalam Al Qur'an Surat Adh-Dhariyat ayat 55 menjelaskan "tetaplah memberi peringatan, karena sesungguhnya peringatan itu bermanfaat bagi orang-orang yang beriman". Nabi Muhammad saw menyatakan bahwa "sampaikanlah olehmu dariku, walaupun hanya satu ayat". Disini setiap muslim berkewajiban untuk menyampaikan pesan dakwah walaupun satu ayat. Pesan dakwah dapat dilakukan dengan berbagai media. Dakwah sendiri merupakan aktifitas amar ma'ruf nahyi munkar (Taufik, 2013). Salah satu tantangan dakwah pada era teknologi dan komunikasi adalah perkembangan masyarakat yang lebih sensitif terhadap lingkungan sekitar (Ahmad, 2014). Penggunaan dan penguasaan pada teknologi informasi dalam dakwah perlu diperkuat (Hasan, 2020).

Perkembangan teknologi dan penggunaan sosial media berpeluang sebagai media dakwah. Para pendakwah sudah waktunya untuk memanfaatkan media baru beserta aplikasinya sebagai sarana dalam berdakwah melalui penggunaan internet yang telah meneguhkan pola dakwah baru (Pardianto, 2013). Penyampaian media dakwah yang menarik secara visual melalui desain grafis sangat diperlukan dalam membidik syiar islam khususnya generasi muda. Generasi muda 
perlu dibekali pemahaman agama yang baik untuk membentengi diri dari berbagai pengaruh lingkungan dan sosial budaya yang kurang baik. Pentingnya syiar agama bagi generasi muda sebab generasi muda adalah tumpuan dan harapan bangsa Indonesia.

Arah dakwah yang dilakukan oleh organisasi menekankan pada pengembangan pendidikan, penguatan ekonomi dan kemanusiaan, dan kesehatan (Hasan, 2020). Salah satu organisasi keputrian Muhammadiyah yaitu Nasyiatul 'Aisyiyah yang bergerak di bidang keagamaan, kemasyarakatan, dan keputrian yang tetap mengedepankan gerakan dakwah amar ma'ruf nahyi munkar seperti yang diamanatkan oleh Muhammadiyah. Salah satu program Nasyiatul 'Aisyiyah adalah bidang dakwah. Bidang tersebut mempunyai terobosan penyiaran ajaran Islam melalui dakwah terpadu. Dakwah terpadu dikembangkan dengan pemanfaatan ilmu pengetahuan dan teknologi (IPTEK). Nasyiatul Aisyiyah khususnya di Kabupaten Banyumas harus mampu merespon positif dan perlu bekal IPTEK dalam kreatifitas dakwah khususnya para generasi muda. Nasyiatul 'Aisyiyah Kabupaten Banyumas terdiri dari 15 cabang yang tersebar di wilayah Banyumas. Berdasarkan visi misi Nasyiatul Aisyiah dan pendekatan dakwah terpadu dengan pendekatan integratif teknologi informasi dan komputer, dituntut kader-kader Nasyiatul Aisyiyah menguasai teknologi. Salah satu media dakwah yang digunakan saat ini adalah penggunaan media sosial. Manfaat media sosial antara lain media komunikasi yang mudah dan tempat mencari informasi yang bermanfaat (Putri et al., 2016). Penggunaan media sosial untuk dakwah memerlukan desain grafis yang menarik. Membuat konten dakwah melalui desain grafis diperlukan penguasaan teknologi komputer. Namun berbagai latar belakang pendidikan dan tidak semua memiliki kemampuan yang sama pada pemanfaatan teknologi khususnya desain maka diperlukan pelatihan desain grafis.
Tujuan kegiatan pelatihan desain grafis yang dilakukan ke mitra adalah meningkatkan kemampuan desain grafis yang digunakan untuk berdakwah dan mengembangkan media dakwah terpadu melalui desain grafis yang menarik. Diharapkan kegiatan pengabdian dapat menjadi salah satu solusi mewujudkan dakwah terpadu yang terintegrasi dengan IPTEK yang dicanangkan oleh Muhammadiyah.

\section{METODOLOGI PELAKSANAAN}

Secara keseluruhan proses tahapan dalam kegiatan pengabdian disajikan pada Gambar 1. Metode pelaksanaan kegiatan yang ditawarkan untuk mencapai tujuan pengabdian sebagai berikut :

1. Pelatihan dan tutorial

Kegiatan pelatihan dan tutorial antara lain penyampaian materi umum tentang software yang dapat digunakan untuk desain grafis dan salah satunya adalah Ms. Power Poin. Ms. Power Poin digunakan disini karena dianggap lebih mudah dipahami dan familiar dipergunakan. Selain itu dalam kegiatan ini peserta pelatihan diberi contohcontoh desain grafis yang menarik untuk syiar. Selanjutnya langsung dilakukan tutorial dan tahapan pembuatan desain grafis dengan $M s$. Power Poin.

2. Praktek

Kegiatan praktek dilakukan agar peserta pelatihan dapat langsung membuat desain grafis sekaligus terdapat sesi tanya jawab dalam praktek pembuatan jika ada hal-hal yang kurang dipahami dan perlu penjelasan lebih rinci melalui praktek.

3. Demonstrasi

Kegiatan demontrasi dilakukan untuk mendemonstrasikan hasil karya yang sudah dibuat peserta di depan kelas.

Beberapa tahapan kegiatan IbM sebelum kegiatan pelaksanaan sebagai berikut: 
1. Koordinasi dengan Ketua Pimpinan Daerah Nasyiatul Aisyiyah Kabupaten Banyumas untuk menunjuk peserta dan berkoordinasi dengan cabang-cabang yang ada di Kabupaten Banyumas untuk mengirimkan peserta pelatihan

2. Mendata jumlah peserta yang akan ikut serta dalam pelatihan

3. Penyiapan alat dan tempat pelatihan

4. Penyiapan materi pelatihan

5. Penggandaan materi pelatihan

6. Di akhir kegiatan akan diadakan evaluasi tentang materi pelatihan dengan memberikan kuisioner yang akan diisi peserta

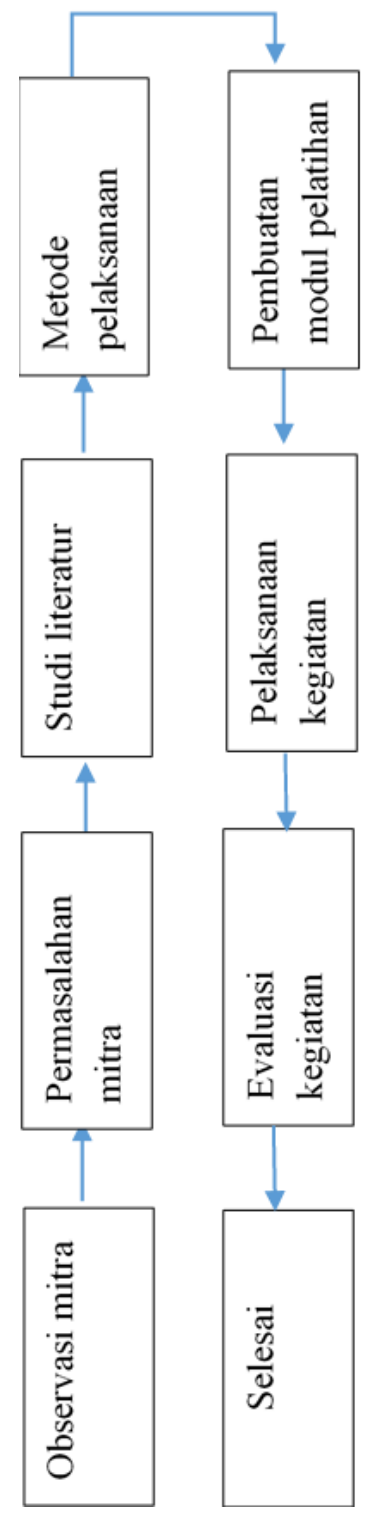

\section{HASIL DAN LUARAN}

Kegiatan diikuti oleh 29 orang dari semua cabang Nasyiatul Aisyiyah termasuk kader Nasyiatul Aisyiyah. Pelaksanaan dilakukan hari Minggu, 21 Januari 2018 dengan tempat di laboratorium multimedia Fakultas Teknik UMP. Pelaksanaan pelatihan disajikan pada Gambar 2., dilaksanakan berdasarkan kesepakatan bersama dengan mitra.

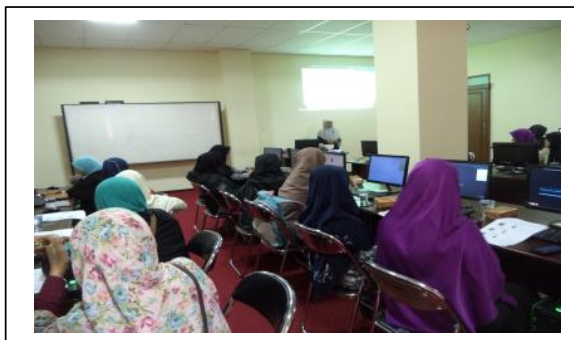

(a) Proses pelatihan \& tutorial

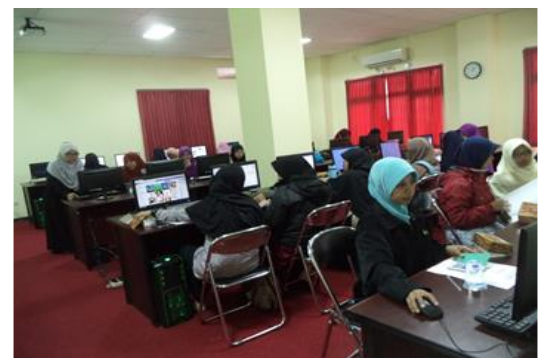

(b) Proses praktek \& tanya jawab

Gambar 2. Pelaksanaan kegiatan pelatihan

Sebelum dilaksanakan pelatihan modul pelatihan diberikan terlebih dulu pada para peserta, sambutan dari wakil ketua PDNA Kabupaten Banyumas, dan dilanjutkan penyampaian materi, tutorial serta praktek yang diakhiri demonstrasi desain grafis yang dibuat peserta. Pelatihan dilaksanakan mulai jam 08.00 sampai dengan jam 14.00 WIB. Diakhir kegiatan pelatihan setelah akhir sesi pelaksanaan demonstrasi dilakukan evaluasi kegiatan melalui sebaran kuisioner yang diisi oleh peserta pelatihan. Diperoleh hasil gambaran umum peserta, evaluasi lokasi dan manfaat pelatihan. Kuisioner yang dapat diolah (terisi semua setiap pertanyaan) diperoleh 27 kuisioner dari 29 kuisioner yang diberikan pada peserta. Gambaran 
umum peserta disajikan pada Tabel 1 . Pendidikan peserta pelatihan $44 \%$ berpendidikan SMA/ SMK, D3 sebesar 15\% dan $41 \%$ berpendidikan sarjana. Ditinjau dari usia peserta pelatihan diketahui bahwa usia kurang dari 20 tahun sebesar $11 \%$, usia 20-30 tahun sebesar 37\%, usia 30-40 tahun sebesar $41 \%$, dan lebih dari 40 tahun sebesar $11 \%$. Kemampuan penggunaan komputer menyatakan bisa menggunakan komputer $48 \%$ sedangkan yang belum (masih dalam tahap belajar) $52 \%$.

Tabel 1. Gambaran umum peserta pelatihan

\begin{tabular}{|c|l|c|c|}
\hline $\begin{array}{c}\text { N } \\
\text { o }\end{array}$ & $\begin{array}{l}\text { Gambaran } \\
\text { umum peserta }\end{array}$ & Jumlah & $\begin{array}{c}\text { Prosenta } \\
\text { se }\end{array}$ \\
\hline 1. & Pendidikan & \multicolumn{2}{|l|}{} \\
\hline & SMA/SMK & 12 & $44 \%$ \\
\hline & D3 & 4 & $15 \%$ \\
\hline & S1 & 11 & $41 \%$ \\
\hline 2. & Usia \\
\hline & $<20$ tahun & 3 & $11 \%$ \\
\hline & $20-30$ tahun & 10 & $37 \%$ \\
\hline & $30-40$ tahun & 11 & $41 \%$ \\
\hline & $\begin{array}{l}>40 \text { tahun } \\
\text { 3. }\end{array}$ & 3 & $11 \%$ \\
\hline & $\begin{array}{l}\text { Kemampuan komputer } \\
\text { Mampu } \\
\text { mengoperasika } \\
\text { n komputer }\end{array}$ & 13 & $48 \%$ \\
\hline & $\begin{array}{l}\text { Tidak mampu } \\
\text { mengoperasika } \\
\text { n / masih } \\
\text { belajar }\end{array}$ & $52 \%$ \\
\hline
\end{tabular}

Sumber : olah data, 2019

Hasil evaluasi kegiatan pelatihan secara keseluruhan disajikan pada Tabel 2. Tabel 2 menjelaskan bahwa fasilitas laboratorium/ komputer sudah memadai dan kenyamanan tempat pelatihan diperoleh jawaban peserta pelatihan sangat setuju 55\%, setuju $41 \%$ dan yang menjawab cukup hanya $4 \%$. Kesesuaian waktu pelatihan dianggap cukup setuju 33\%, setuju 37\% dan sangat setuju $30 \%$. Materi pelatihan yang disampaikan menambah pengetahuan diperoleh jawaban peserta sangat setuju $67 \%$ dan setuju 33\%. Materi yang disampaikan bermanfaat dalam pekerjaan diperoleh jawaban responden menyatakan sangat setuju 59\%, setuju $37 \%$ dan yang hanya menjawab cukup setuju $4 \%$.
Tabel 2. Evaluasi kegiatan

\begin{tabular}{|c|l|c|c|}
\hline No & \multicolumn{1}{|c|}{$\begin{array}{c}\text { Evaluasi } \\
\text { kegiatan }\end{array}$} & Jumlah & Prosentase \\
\hline 1. & $\begin{array}{l}\text { Fasilitas laboratorium / } \\
\text { dinyatakan sudah memadai }\end{array}$ \\
\hline & Sangat setuju & 15 & $55 \%$ \\
\hline & Setuju & 11 & $41 \%$ \\
\hline & Cukup & 1 & $4 \%$ \\
\hline 2. & Kenyamanan tempat pelatihan \\
\hline & Sangat setuju & 15 & $55 \%$ \\
\hline & Setuju & 11 & $41 \%$ \\
\hline & Cukup & 1 & $4 \%$ \\
\hline 3. & Kesesuaian waktu pelatihan \\
\hline & Sangat setuju & 8 & $30 \%$ \\
\hline & Setuju & 10 & $37 \%$ \\
\hline & Cukup & 9 & $33 \%$ \\
\hline 4. & $\begin{array}{l}\text { Materi yang disampaikan } \\
\text { pengetahuan }\end{array}$ \\
\hline & Sangat setuju & 18 & $67 \%$ \\
\hline & Setuju & 9 & $33 \%$ \\
\hline 5. & Materi memberi manfaat pada pekerjaan \\
\hline & Sangat setuju & 16 & $59 \%$ \\
\hline & Setuju & 10 & $37 \%$ \\
\hline & Cukup & 1 & $4 \%$ \\
\hline
\end{tabular}

Sumber : olah data, 2019

Berdasarkan hasil wawancara dan diskusi yang dilakukan dengan peserta pelatihan, materi pelatihan desain grafis banyak bermanfaat pada syiar melalui media sosial. Syiar melalui media sosial potensial untuk generasi muda. Pengguna media sosial berusia 13-19 tahun atau sekitar 73juta pengguna berpotensi mempopulerkan konten sains Islam (Irwandani, 2016). Media sosial sebagai medium dakwah memberi eksistensi seorang pendakwah dalam bersyiar tiada henti tanpa sekat ruang dan waktu (Suhatro, 2017). Pelatihan desain grafis juga bermanfaat bagi para peserta pelatihan khususnya pekerjaan di organisasi PDNA Kabupaten Banyumas sebagai contoh ketika ada pekerjaan mendesain brosur dan lainnya terkait sosialisasi kegiatan dan program-program Nasyiatul Aisyiyah. Disamping itu pelatihan desain grafis dengan menggunakan Microsoft Power Poin menambah kemampuan para peserta khususnya dalam penyampaian presentasi yang menarik dengan menyajikan gambar/ grafis dalam mendukung syiar islam terpadu teknologi. Keberadaan 
organisasi Nasyiatul Aisyiyah sebagai gerakan putri Islam mempunyai keterikatan pada pencerahan dan pemberdayaan yang merupakan modal sosial bangsa Indonesia (Ahdiah, 2011).

\section{KESIMPULAN DAN SARAN}

Hasil dari evaluasi kegiatan dapat disimpulkan bahwa pelatihan desain grafis dapat meningkatkan kemampuan dan pengembangan dakwah. Desain grafis sebagai media dakwah mempermudah penyampaian syiar melalui media sosial. Disamping itu pelatihan memberi manfaat pada pekerjaan khususnya di organisasi PDNA Kabupaten Banyumas. Namun dalam mendesain konten dakwah yang secara visual menarik diperlukan kreatifitas desain grafis yang mudah dipahami oleh khalayak umum.

\section{DAFTAR PUSTAKA}

Ahdiah, I. (2011). Organisasi perempuan sebagai modal sosial. JURNAL ACADEMICA, 03(01), 523-534.

Ahmad, N. (2014). Tantangan Dakwah Di Era Teknologi Dan Informasi: Formulasi Karakteristik, Popularitas , dan Materi di Jalan Dakwah. Addin, 8(2), 319-344.

Hasan, J. (2020). Tantangan Dan Arah Dakwah Di Tengah Ancaman Pandemi Covid-19. Jurnal Peurawi: Media Kajian Komunikasi Islam, 3(2), 46-60. https://www.jurnal.arraniry.ac.id/index.php/peurawi/article /view/7919

Irwandani, I. (2016). Potensi Media Sosial dalam Mempopulerkan Konten Sains Islam. Potensi Media Sosial Dalam Mempopulerkan Konten Sains Islam, 1(2), 173. https://doi.org/10.24042/tadris.v1i2.1 065

Pardianto. (2013). Meneguhkan Dakwah Melalui New Media. Jurnal Komunikasi Islam, 03, 146-166. http://jki.uinsby.ac.id/index.php/jki/ar ticle/view/12

Putri, W. S. R., Nurwati, N., \& S., M. B. (2016). Pengaruh Media Sosial Terhadap Perilaku Remaja. Prosiding KS: Riset \& PKM, 3(1). https://doi.org/10.24198/jppm.v3i1.1 3625

Suhatro, S. (2017). Media Sosial Sebagai Medium Komunikasi Dakwah. AlMishbah, 03(2).

Taufik, T. (2013). Dakwah Era Digital Seri Komuikasi Islam (e-book edi). Pustaka Al Ikhlash. 